\title{
100 Things Every College Student with a Disability Ought to Know
}

\author{
by Kendra D. Johnson and Trudie N. Hines
}

Published by the Cambridge-Stratford Study Skills Institute, 2005, 229 pages

Reviewed by

Robyn Hudson (robynhud@vt.edu), Assistant Director, Services for Students with Disabilities, Virginia Tech

Making a smooth transition to college life is a challenge for most students. Students with disabilities have additional needs and challenges that they must address in addition to adapting to regular developmental processes. The transition to college can be unnecessarily difficult for students with disabilities if they do not understand what is expected of them in regards to their disabilities and if they are not properly oriented to the institutional environment and protocols. Transition and orientation challenges can range from having acceptable documentation of a disability to locating the right services offices, asking for assistance, managing health needs, negotiating inaccessible environments, and coping with real or perceived stigma or discrimination. Just as multicultural affairs offices are not solely responsible for the successful transition of students of color, campus disability services are not singularly responsible for transitioning and orienting students with disabilities. Successful transition, adaptation to college life, strong academic performance, and persistence to graduation for students with disabilities requires a holistic approach from many different parties and points of contact.

The process of a successful transition to college and full participation centers around the interaction of 1) institutional climate and accessibility, and 2) students with disabilities' self-awareness, advocacy, and efficacy. In 100 Things Every College Student with a Disability Ought to Know, Johnson and Hines address the most salient and frequent transition issues for college students with disabilities. They provide a mini-orientation to the ins and outs of being a student with a disability on most U.S. college campuses.

The Cambridge-Stratford Study Skills Institute has developed a series of training materials for educators to improve students' study skills and learning in secondary and post-secondary education (Cambridge-Stradford, 2011). The format and brand of this series of books addresses topics in a series of 100 statements. For students with learning disabilities or attention deficits that affect the desire to read, this format may be particularly appealing.

The authors gave 100 specific pieces of advice on a range of relevant topics for students with disabilities. The topics are grouped into seven categories that relate 
to transitioning and adapting to the college environment. The seven categories are Arriving, Paperwork, Leveling the Playing Field, The Classroom Experience, Campus Life, and Success Strategies (p. viii-ix). The sequence of the seven sections parallels the process of registering for disability services, engaging faculty, and taking full advantage of college life.

Each of the 100 pieces of advice is on a separate page, peppered with humorous cartoons related to disability issues. The following is an example of how this appears:

Students with a Disability Ought to Know: that in order to receive accommodations, you are responsible for contacting the Disability Support Services (DSS) office. In any educational setting after high school, you will need to identify your need for accommodations. Even if you received special education services in high school, the college is not aware of that fact. The office may have a different name like Accessibility Services, Office of Accessibility, Handicapped Resource Center, or similar-but there will be an office. (p. 12)

Quotes from students with disabilities are included. For example, "'Know what you need and don't be afraid to ask for it.' Cindy, sophomore, blind" (p. 44). The use of student quotations lends credibility to the advice given. There are short checklists in each chapter that students and parents can use to prepare students with disabilities for the challenges of college transition, academics, and life.

100 Things stresses that students are primarily responsible for attaining accommodations and services on campus by notifying campus disability services providers early (p. 18). Students need to understand the difference between high school and college in terms of relevant legislation and expectations (IDEA versus $\mathrm{ADA}$ ), and that what worked in high school does not translate directly to college. Other things that college students with disabilities ought to know are how the admissions process relates to students with disabilities, documentation requirements, and the critical importance of timely notification of needs. 100 Things encourages students to utilize on- and off-campus resources and to have a working knowledge of these resources prior to starting school. Students could be provided a copy of the book when visiting a disability services office for the first time. Disability services staff could use the book as a resource for structuring orientation programming for students who have disabilities. Parents may be more apt to read it, but they too have many misconceptions about disability services for their student that need to be addressed.

To address students' hesitancy to disclose their disability or request accommodations, Johnson and Hines normalize the feelings of students and assure them that most interactions with peers, faculty, and administrators will be positive ones. They explain that reasonable accommodations are intended to level the playing field and that the process of obtaining accommodations and services is interactive and carried out on a case-by-case basis with a disability service provider in a confidential setting. Students with disabilities have many questions about types of accommodations, disclosure, fairness, and they have fears that registering as a student with a disability will "follow" them on their academic transcripts. 100 
Things also addresses study strategies, asking for help, managing realistic course loads, meeting the fundamental requirements of courses and programs, adhering to conduct codes, having positive social interactions, and requesting housing modifications.

I recently had a conversation with a student who was diagnosed with significant learning disabilities in high school, but waited several years to seek accommodations and services in college. He said that his high school special education coordinator told him that colleges do not accommodate students who do well in high school. The information he was given was entirely inaccurate. The student struggled with academics, earning marginal grades for several years. 100 Things would be a valuable tool on the desks of high school transition and guidance counselors. The information in the book is a must-have for high school transition counselors.

Because almost every student affairs professional will encounter students with disabilities, this book would be especially helpful in providing clear and concise training for professionals on the basics of disability in higher education. Sometimes it is difficult to answer questions from students and parents directly, clearly, and accurately. The authors provide concise statements to answer common questions. The book covers topics over a wide range of student affairs such as housing accommodations, service animals, career development, campus engagement, and conduct issues. The book is appropriate for admissions personnel, orientation staff, dean of students, housing specialists, counseling and health center staff, student conduct officers, and career services staff. Student affairs personnel should be familiar with basic ADA legislation and the accommodations process on campus.

The section on Campus Life includes things students with disabilities ought to know such as, "Finding a good roommate match is a challenge for all students, but can be significantly more challenging for students with disabilities" (p. 106), and that "you should not expect your college roommate to provide special services to you" (p.107). Although service animals are allowed in residence halls, "pets are not service animals" (p. 110).

Students with disabilities are less likely to take advantage of extracurricular opportunities. Students with a disability ought to know that

campus work, co-ops, and internships are a must for all students in today's competitive world, but even more so for students with disabilities.

Demonstrating your work ability before graduation goes a long way to dispel myths and stereotypes that exist in the workplace about individuals with disabilities. (p. 150)

The book stays in line with the look and format of the Cambridge study skills series, but this look is somewhat outdated. An updated look, perhaps with a more interactive format, would enhance the appeal of this resource. Johnson and Hines should also update a second edition with more information on the types of disabilities that students have, especially in light of the re-authorization of the Americans with Disabilities Act of 2009. The book is provided in alternate text format for individuals with print-related disabilities. 
100 Things is not intended to address all the issues that disability services providers encounter, but it is a good starting point for communicating basic information to students about college life as a student with a disability using a positive and balanced approach. 100 Things Every College Student with a Disability Ought to Know can be used as a stand-alone resource for students or as part of comprehensive orientation service for disability services programs on college campuses.

\section{References}

Cambridge-Stratford Study Skills Institute. 2011. Accessed December 2, 2011 http://www.cambridgestratford.com/index.html 